e-ISSN: 2564 - 6664

DOI:10.33716/bmedj.858718
1,2,3 Dr. Öğr. Üyesi, Balıkesir Üniversitesi, Tıp Fakültesi, Acil Tıp Bölümü, Balıkesir Türkiye

Sorumlu Yazar: Salih Kocaoğlu, Balıkesir

Üniversitesi, Tıp Fakültesi, Acil Tıp Bölümü, Balıkesir Türkiye. E-mail: salihkocaoglu1986@gmail.com. Telefon: 026661210 10/1406.

Başvuru Tarihi: 11.01.2021

Kabul Tarihi: 09.04.2021 Yayınlanma Tarihi: 25.06.2021

Atff Iç̧in: Salih Kocaoğlu, Non-Ketotik Hiperglisemiye Bağlı Gelişen Hemikore-Hemiballizm, Balıkesir Medical Journal, 2021;5(2):117-118

\title{
Non-Ketotik Hiperglisemiye Bağlı Gelişen Hemikore-Hemiballizm
}

\author{
Hemichorea-Hemiballism Due to Non-Ketotic Hyperglycemia
}

Salih Kocaoğlu' ${ }^{1}$, (D) Hasan Basri Çetinkaya ${ }^{2}$, (D) Tufan ALATLI ${ }^{3}$,

\section{öz}

Kore-ballismus nonketotik hipergliseminin nadir görülen bir komplikasyonu olarak tip 2 diyabetli hastalarda görülebilir. Kan şekeri regülasyonu sonrası acil servise sağ kolda istem dışı hareketler ile gelen ve yapılan tetkiklerinde hiperglisemiye sekonder hemikore-hemiballismus geliştiği tespit edilen bir hastayı literatürde nadir rastlandığı için sunduk ve patofizyolojide sorumlu mekanizmaları inceledik.

Anahtar Kelimeler: hemikore; hemiballizm; kore,ballismus; diyabet; non-ketotik

\section{ABSTRACT}

Chorea-ballismus may be seen in patients with type 2 diabetes as a rare complication of nonketotic hyperglycemia. We presented a patient who came to the emergency department with involuntary movements in the right arm after blood glucose regulation and who developed hemichoreahemiballismus secondary to hyperglycemia, because it is rare in the literature, and we examined the mechanisms responsible in pathophysiology.

Keywods: hemichorea; hemiballism; chorea; ballismus; diabetes; nonketotic

GíRiş

Kore; istem dışı, ani gelişen, bir uzuvdan diğerineyayılan, vücudun rastgele heryerinde olabilen, kısa süreli ve düzensiz kas kasılmalarıdır (1,2). Ballismus ise daha çok kolve bacakların şiddetli, ani, kontrolsüz, genişamplitüdlü ve proksimal hareketlerini tanımlamak için kullanılır. Bu istemsiz hareketler vücudun bir tarafinı tuttuğunda hemiballismus-hemikore adlarını alırlar (3). Bu hareketlerin etyolojisinde başta serebrovasküler hastalıklar olmak üzere, metobolik, dejeneratif, enfeksiyöz süreçler, yer kaplayan lezyonlar, ilaçlar ve toksik maddelere bağlı gelişen bazal gangliyon hasarı rol alır (4-6). Biz bu makalede nadir olarak görülen hiperglisemi ile ilişkili hemikorehemiballismus tanısı konan tip 2 diyabetli bir hastayı inceledik ve patofizyolojide sorumlu mekanizmaları irdeledik.

OLGU

68 yaşında bayan hasta sağ kolda olan istem dışı hareketler şikayetiyle acil servise getirildi. Dört gün önce acil servisimize hiperglisemi nedeniyle başvuran ve kan şekeri regülasyonu sonrası eksterne edilen hastanın ertesi gün istemsiz hareketlerinin başladığı öğrenilmiştir. Hastanın özgeçmişinde 15 yıldır diyabet hastası olduğu ve oral antidiyabetik kullandığı öğrenilmiştir. Fizik muayenede bilinç açık, oryante, koopere, anlama ve konuşma tamdı. Motor muayenesinde kas gücü kaybı yok, sağ üst ekstremitede belirgin koreiform hareketler mevcuttu. Duyu muayenesi doğal, serebellear testler becerikliydi. Fasyal asimetri saptanmadı. Laboratuar incelemesinde kan şekeri $347 \mathrm{mg} / \mathrm{dl}$ (4 gün önce $463 \mathrm{mg} / \mathrm{dl}$ ), Na $135 \mathrm{mEq} / \mathrm{L}$, serum osmolaritesi $300 \mathrm{mOsm} / \mathrm{kg}, \mathrm{pH}$ 7.41, idrarda keton negatif, üre $60 \mathrm{mg} / \mathrm{dl}$ saptandı. Hastanın diğer biyokimya ve hemogram incelemeleri normal aralıktaydı. Kraniyal BT ve difüzyon MR'da patolojik görüntü yoktu. Hasta bu bulgularla nonketotik hiperglisemi ile ilişkili hemikore-hemiballismus tanısı konularak nöroloji kliniğine yatırıldı. Hastanın ilgili serviste kan şekeri regülasyonu ve $10 \mathrm{mg} /$ gün haloperidol tedavisi ile 3. gününde semptomları tamamen düzeldi. Hasta bilgilendirilmiş ve aydınlatılmış onam formu alınmıştır. 


\section{TARTIŞMA}

Hiperglisemi ile ilişkili hareket bozuklukları korea veya ballismus şeklinde görülebilir. İnmeden sonra hemiballismusun en sık nedeni hiperglisemi olarak bilinmektedir (7). Özellikle ileri yaşlarda kan şekeri iyi kontrol altına alınamayan diyabetik hastalarda görülmektedir $(5,8)$. Bizim hastamızın da mevcut durumu benzerdi. Non ketotik hiperglisemiye bağlı hemikore ve hemiballismusun nasıl geliştiği tam anlamıyla aydınlatlamamıştı. Literatürde yapılmış bazı çalışmalarda hemikorenin geliştiği ekstremitenin karşı tarafinda bazal gangliyonlarda kan akımı ve glikoz metabolizmasının azaldığı PET ve SPECT incelemeleriyle gösterilmiştir $(9,10)$. Bazal gangliyonlarda hiperglisemiye bağlı striatumda dopaminerjik aktivitenin artması, hipervisközite sonucu kan beyin bariyenin bozulması, striatumda oluşan peteşiyel kanamalar veya enfarktlar bunun nedeni olarak gösterilmiştir (5). Hareket bozukluğunun daha çok vasküler bir patolojiye mi yoksa metabolik bir duruma mı sekonder oluştuğu tam anlamıyla anlaşılamamıştır. Tedavi sonrası hastalarda kan glukoz düzeyinin normale dönmesi sonucu semptomların düzelmesi metobolik bir durumu düşündürürken, bazı vakalarda olayın akut başlaması ise vasküler ani gelişen bir patofizyolojiyi akla getirmektedir. Kan şekerinin normale dönmesine rağmen hareket bozukluğunun sebat etmesi, koreatotik hareketlerin daha çok vücudun bir tarafinda görülmesi, vasküler bir mekanizmayı gösterirken; bilateral ekstremitelerde görülen vakalar ve yapılan otopsi çalışmalarında striatal bölgede yalnızca nöron kaybı ve reaktif astrositozun görülmesi, enfarkt yada hemorajiye rastlanmaması vasküler patolojiye ters düşmektedir $(11,12)$.

Chang ve arkadaşlarının 18 olgudan oluşan çalışmasında hastaların akut ve remisyon döneminde yapılan kraniyal $M R$ ve $M R$ spektroskopi görüntülerine dayanılarak bu klinik tablonun hipergliseminin potansiyelize ettiği geçici bir iskemi nedeniyle gelişmiş olabileceğini savunmaktadır (13). Hastaların radyoloji incelemesinde T1 ağırlıklı görüntülerde striatumda hiperintens alan görülmesi tipiktir (14). Ayrıca difüzyon MR incelemesinde difüzyon kısıtlılığı görülebilir (15). Ancak bizim hastamızda kranyal BT ve difüzyon MR incelemesinde akut patoloji saptanmamıştr.

Patofizyoloji tam olarak aydınlatılamamış olsa da hastaların büyük çoğunluğunda semptomlar kan şekeri regülasyonu ile kısa sürede düzelmektedir. Bizim olgumuzda da literatür ile uyumlu olarak kan

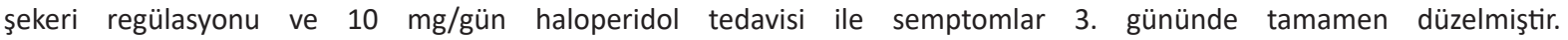
Ancak hastaların \%20'sinde hareket bozukluğunun 3 aydan fazla devam edebildiği bilinmektedir (4).

\section{SONUÇ}

Korea ve ballismus gibi hareket bozukluğu ile gelen diyabetik hastalarda non-ketotik hipergliesmiye bağlı bu durumun gelişebileceği unutulmamalı ve ayırıcı tanı yapılırken zaman kaybetmeden kan şekeri regülasyonu sağlanmalıdır.

\section{KAYNAKLAR}

1. Gul HL, Kocer A, Sargin H, Boru UT. Hyperosmolar Nonketotic Hyperglusemia Related Chorea-ballismus. Endokrinolojide Yönelişler 2005;14:24-25.

2. Apaydın H, Hanağası H, Kore ve hemiballismus:Fenomenoloji ve tedavi. Parkinson Hast Hareket Boz Der 2007;10:62-71.

3. Weiner WJ, Lang AE: Movement disorders a comprehensive survey, Futura Publishing Company, Mount Kisco, New York, 1989.

4. Mihai CM, Catrinoiu D, Stoicescu RM. Atypical onset of diabetes in a teenage girl: a case report. Cases Journal 2008;1:425.

5. Lin JJ, Chang MK. Hemiballism-hemichorea and non-ketotic hyperglycaemia. Journal of Neurology Neurosurgery and Psychiatry 1994;57:748-750.

6. Awasthi D, Tiwari AK, Upadhyaya A, Singh B, Tomar GS. Ketotic hyperglycemia with movement disorder. J Emerg Trauma Shock 2012;5:90-91.

7. Postuma RB, Lang AE. Hemiballism: revisiting a classic disorder. Lancet Neurol 2003; 2:661-668.

8. Narayanan S. Hyperglycemia-induced Hemiballismus Hemichorea: A Case Report and Brief Review of the Literature. J Emerg Med 2010; 19:1-3.

9. Kim JS, Lee KS, Lee KH, Kim YI, Kim BS, Chung YA, Chung SK. Evidence of thalamic disinhibition in patients with hemichorea: semiquantitative analysis using SPECT. J Neurol Neurosurg Psychiatry 2002;72:329-333.

10. Hsu JL, Wang HC, Hsu WC. Hyperglycemia-induced unilateral basal ganglion lesions with and without hemichorea. A PET study. J Neurol 2004;251:1486-1490.

11. Shan DE, Ho DM, Chang C, Pan HC, Teng MM. Hemichorea - hemiballism: an explanation for MR signal changes. Am J Neuroradiol 1998; 19:863-870.

12. Ohara S, Nakagawa S, Tabata K, Hashimoto T. Hemiballism with hyperglycemia and striatal T1-MRI hyperintensity: an autopsy report. Mov Disord 2001; 16:521-525.

13. Chang KH, Tsou JC, Chen ST, Ro LS, Lyu RK, Chang HS, Hsu WC, Chen CM, Wu YR. Temporal features of magnetic resonance imaging and spectroscopy in non-ketotic hyperglycemic chorea-ballism patients. Eur J Neurol 2010; 17:589-593.

14. Ergün T, Lakadamyalı H. Hemichorea-Hemiballismus due to Non-Ketotic Hyperglycemia. Turk Norol Derg 2013;19:73.

15. Oh SH. Chorea associated with non-ketotic hyperglycemia and hyperintensity basal ganglia lesion on T1-weighted brain MRI study: a meta-analysis of 53 cases including four present cases. J Neurol Sci 2002;200:57-62. 